\title{
Effects of Urban Park on Atmospheric Purification in Seoul
}

\author{
Hyun-Kil Jo \\ Department of Ecological Landscape Architecture Design, Kangwon National University \\ Chuncheon 24341, Republic of Korea \\ jhk@kangwon.ac.kr
}

\section{Extended Abstract}

Increasing concentrations of air pollutants, which negatively affect human health and ecosystems, are a serious environmental concern in the world. Our society has made various efforts to reduce air pollutants, such as $\mathrm{SO}_{2}, \mathrm{NO}_{2}$, and $\mathrm{O}_{3}$. Tree planting in the urban environment could contribute to reducing concentrations of air pollutants. However, little information is available regarding atmospheric purification effects by urban trees. The purpose of this study was to quantify annual uptake of $\mathrm{SO}_{2}, \mathrm{NO}_{2}$, and $\mathrm{O}_{3}$ by urban parks in Seoul, Korea and to suggest planting strategies to improve atmospheric purification effects.

A stratified sampling method was applied to select sample parks on aerial photographs with a scale 1:1,000. Eight straight lines radiating from the center of the study city were drawn in eight different directions of the same angle, and subsequently circles were drawn $40 \mathrm{~cm}$ apart. This study sampled a total of 35 parks at which the circles and lines coincided, and field-surveyed all the trees planted in each park. The number of sample parks was a compromise between the competing concerns for the reliability of data and the availability of expense. Surveyed tree data included species, stem diameter, height, crown width, and density. These data were used to compute annual uptake of the air pollutants by trees, based on quantitative models derived from measurements of deposition velocity by pollutant [1] and leaf area by tree species and size [2].

Mean tree density and cover in the study parks were 22.4 trees $/ 100 \mathrm{~m}^{2}$ and $50.1 \%$, respectively. Trees with stem diameter at breast height of less than $30 \mathrm{~cm}$ accounted for $79.3 \%$ of all the trees. Annual uptake per unit area of the air pollutants by the trees averaged $11.5 \mathrm{~kg} / \mathrm{ha} / \mathrm{yr}$ for $\mathrm{SO}_{2}, 36.8 \mathrm{~kg} / \mathrm{ha} / \mathrm{yr}$ for $\mathrm{NO}_{2}$, and $26.7 \mathrm{~kg} / \mathrm{ha} / \mathrm{yr}$ for $\mathrm{O}_{3}$. Total annual uptake of the pollutants for entire park area in the study city was approximately $48 \mathrm{t} / \mathrm{yr}$ for $\mathrm{SO}_{2}, 152 \mathrm{t} / \mathrm{yr}$ for $\mathrm{NO}_{2}$, and $110 \mathrm{t} / \mathrm{yr}$ for $\mathrm{O}_{3}$. Total annual emissions of $\mathrm{SO}_{2}$ and $\mathrm{NO}_{2}$ from energy consumption in the study city were about 3,527 t/yr and 62,350 t/yr, respectively [3]. Seoul's urban parks annually offset the $\mathrm{SO}_{2}$ emissions by $1.4 \%$ and the $\mathrm{NO}_{2}$ emissions by $0.2 \%$. This study explored desirable planting strategies including minimization of extensive grass area, full planting in available growing spaces, and multilayered and multi-aged tree planting. These study results could be useful in informing the public of atmospheric purification effects by urban parks.

\section{Acknowledgement}

This study was carried out with the support of the 'R\&D Program for Forest Science Technology (Project No. 2017043 B10-1819-BB01)’ provided by the Korea Forest Service (Korea Forestry Promotion Institute).

\section{References}

[1] A. C. Hill, "Vegetation: a sink for atmospheric pollutants," J. the Air Pollution Control Association, vol. 21, no. 6, pp. 341-346, 1971.

[2] H. K. Jo, Indicator for $\mathrm{CO}_{2}$ Uptake and Atmospheric Purification Evaluation of Vegetation. Development of EcoIndicators for Sustainable Development. Seoul: Ministry of Environment, 2001.

[3] NIER (National Institute of Environmental Research), (2018, January 30). Annual Emissions of Air Pollutants. [Online].

Available: http://airemiss.nier.go.kr/module/statistics/pollutantsStatistics.do?siteId=airemiss\&id=airemiss_030400000000 